\title{
PERILAKU PERAWAT DALAM MEMBUANG LIMBAH MEDIS DI RSUD dr. SAYIDIMAN MAGETAN TAHUN 2014
}

\author{
Vina Septi Andriyani, Sri Poerwati, Handoyo
}

\begin{abstract}
Medical wastes need to be handled properly. The forefront of this efforts is the waste generation node. The health worker who are responsible for waste generation are nurses at the nursing wards. The the nurses were in the forefront and determine the fate of the medical waste treatment in a hospital. The purpose of this study is to reveal nurses' behavior pertaining to the management of medical waste.

Data were collected through interviews and observation of the behavior of the nurses on the morning duty, than analyzed the data descriptively.

Results showed that $64 \%$ of waste generation location has made efforts in the sorting of wastes, but all of them $(100 \%)$ has not been doing well in stowage. It is not easy to understand, since $75 \%$ of the nurses have good knowledge, but only $54 \%$ who carry out the disposal of medical waste properly. Therefore it is advisable to provide support to medical waste disposal facilities throughout the waste generating rooms and implementing reward and punishment system for those who should do so.
\end{abstract}

\section{Keywords: medical wastes. Nurse, generation}

\section{PENDAHULUAN}

Kebutuhan akan perlunya pengelolaan limbah medis saat ini tidak hanya dirasakan oleh rumah sakit dan pusat-pusat medik saja, tetapi mencakup pula penghasil limbah berskala kecil seperti klinik, akademi dan universitas, laboratorium diagnostik, perusahaan farmasi dan bioteknologi, tempat praktik dokter dan fasilitas pelayanan kesehatan lainnya. Limbah Medis tiap unit pelayanan dalam Rumah Sakit dikumpulkan oleh tenaga perawat, khususnya yang menyangkut pemisahan limbah medis dan non medis, sedang ruang lain bisa dilakukan oleh tenaga kebersihan.

Perawat memiliki tugas untuk mengurangi/menghilangkan efek negatif dari hasil lingkungan limbah medis seperti apa yang dijelaskan oleh ICN dan National

Nurses Association (NNAs) sebagai organisasi perwakilan perawat.

Organisasi Kesehatan Dunia (WHO) bersama Departemen Kesehatan pada 1997 melakukan survey pengelolaan limbah di 88 rumahsakit diluar Kota Jakarta. Berdasarkan kriteria WHO, pengelolaan limbah rumah sakit yang baik bila persentase limbah medis $15 \%$. Tetapi, di Indonesia mencapai $23,3 \%$. Survey juga menemukan rumah sakit yang memisahkan limbah 80,7\%, melakukan pewadahan $20,5 \%$, pengangkutan $72,7 \%$. (Asmadi, 2013)

Di RSUD dr. Sayidiman Magetan pada ruangan yang menghasilkan limbah medis terlihat perawat lebih banyak berperan dalam hal melakukan tindakan pelayanan keperawatan kepada pasien (seperti: menyuntik, memasang selang infus, mengganti cairan infus, memasang selang urine, dan perawatan luka kepada pasien, perawatan dalam pemberian obat) sehingga dipastikan perawatlah yang pertama kali berperan, limbah medis berada pada tempat yang aman atau tidak (tempat pengumpulan sementara alat-alat medis yang sudah tidak dipakai lagi), sebelum dikumpulkan dan diangkut ke tempat pengelolaan akhir oleh petugas pengangkut limbah rumah sakit.

Dari ruangan-ruangan penghasil limbah medis seperti perban dan kapas bercampur darah, infuset bekas, sarung tangan bekas dan jarum suntik bercampur dengan limbah non medis. Meskipun disana sudah disediakan tempat sampah dan sudah tertera jenis-jenis sampah yang dimaksud.

Berkenaan dengan hal diatas maka peneliti ingin melakukan Studi Tentang Perilaku Perawat dalam Membuang Limbah Medis di RSUD dr. Sayidiman Magetan Tahun 2014. 


\section{TUJUAN PENELITIAN}

Untuk mengetahui Perilaku Perawat dalam Membuang Limbah Medis di RSUD dr. Sayidiman Magetan, yang dirinci menjadi:

a. Mendata produksi limbah medis di RSUD dr. Sayidiman Magetan.

b. Menilai pengetahuan perawat dalam membuang limbah medis di RSUD dr. Sayidiman Magetan.

c. Menilai sikap perawat dalam membuang limbah medis di RSUD dr. Sayidiman Magetan.

d. Menilai tindakan perawat dalam membuang limbah medis di RSUD dr. Sayidiman Magetan.

\section{METODE PENELITIAN}

\section{Jenis Penelitian}

Jenis penelitian yang digunakan adalah deskriptif

\section{Populasi Penelitian}

Populasi dalam penelitian ini adalah seluruh perawat yang bertugas di ruangan-ruangan penghasil limbah medis sebanyak 171 perawat. Besar sampel dalam penelitian ini adalah 56 perawat yang menghasilkan sampah medis pada sift pagi dengan metode total sampling.

\section{Teknik Pengumpulan Data}

Teknik pengumpulan data dilakukan dengan Wawancara,

Observasi/pengamatan langsung.

Analisis Data: secara deskriptif.

\section{HASIL PENELITIAN}

Timbulan Limbah Medis oleh Perawat di Ruangan-ruangan Penelitian di RSUD dr. Sayidiman Magetan Tahun 2014. Semua ruang perawatan menghasilkan limbah medis dalam jenis dan volume yang beragam.

Tabel 1. Ketersediaan Pewadahan Limbah Medis di RSUD dr. Sayidiman Magetan Tahun 2014

\begin{tabular}{|c|l|c|c|}
\hline No & Kategori & $\boldsymbol{\Sigma}$ & $\mathbf{\%}$ \\
\hline 1 & Baik & 9 & 82 \\
\hline 2 & Cukup & 2 & 18 \\
\hline 3 & Kurang & 0 & 0 \\
\hline \multicolumn{2}{|c|}{ Jumlah } & $\mathbf{1 1}$ & $\mathbf{1 0 0}$ \\
\hline
\end{tabular}

Tabel 2. Karakteristik Usia Perawat dalam Membuang Limbah Medis di RSUD dr. Sayidiman Magetan Tahun 2014

\begin{tabular}{|c|c|c|c|}
\hline No & Umur (Tahun) & $\boldsymbol{\Sigma}$ & $\%$ \\
\hline \multirow[t]{5}{*}{1} & $21-25$ & 12 & 21,4 \\
\hline & $26-30$ & 25 & 44,7 \\
\hline & $31-35$ & 8 & 14,2 \\
\hline & $>36$ & 11 & 19,7 \\
\hline & Jumlah & 56 & 100 \\
\hline \multirow[t]{7}{*}{2} & Pendidikan & $\Sigma$ & $\%$ \\
\hline & S2 Keperawatan & 0 & 0 \\
\hline & S1 Keperawatan & 15 & 26,8 \\
\hline & Sarjana Saint Terapan & 1 & 1,80 \\
\hline & DIII Keperawatan & 40 & 71,4 \\
\hline & SPK/Jurkes & 0 & 0 \\
\hline & Jumlah & 56 & 100 \\
\hline \multirow[t]{13}{*}{3} & Ruangan Bekerja & $\bar{\Sigma}$ & $\%$ \\
\hline & $\begin{array}{ll}\text { Paviliun } & \text { Wijaya } \\
\text { Kususma } & \end{array}$ & 7 & 12,5 \\
\hline & IGD & 5 & 8,92 \\
\hline & IBS & 10 & 17,8 \\
\hline & Poliklinik Gigi & 2 & 3,6 \\
\hline & Poliklinik Bedah & 3 & 5,4 \\
\hline & IRNA I & 3 & 5,4 \\
\hline & IRNA II & 5 & 8,9 \\
\hline & IRNA III & 7 & 12,5 \\
\hline & IRNA IV & 4 & 7,14 \\
\hline & IRNA V & 5 & 8,92 \\
\hline & IRNA VI & 5 & 8,92 \\
\hline & Jumlah & 56 & 100 \\
\hline \multirow[t]{6}{*}{4} & Lama Bekerja & $\Sigma$ & $\%$ \\
\hline & $<1$ tahun & 2 & 3,6 \\
\hline & $2-4$ tahun & 24 & 42,9 \\
\hline & $5-9$ tahun & 13 & 23,2 \\
\hline & $>10$ tahun & 17 & 30,3 \\
\hline & Jumlah & 56 & 100 \\
\hline
\end{tabular}

Tabel 3. Tingkat Pengetahuan Perawat dalam Membuang Limbah Medis di RSUD dr. Sayidiman Magetan

\begin{tabular}{|c|l|c|c|}
\hline No & $\begin{array}{c}\text { Kategori } \\
\text { Pengetahuan }\end{array}$ & $\boldsymbol{\Sigma}$ & $\mathbf{\%}$ \\
\hline 1 & Baik & 42 & 75 \\
\hline 2 & Cukup & 14 & 25 \\
\hline 3 & Kurang & 0 & 0 \\
\hline & Jumlah & $\mathbf{5 6}$ & $\mathbf{1 0 0}$ \\
\hline
\end{tabular}

Tabel4. Sikap Perawat dalam Membuang Limbah Medis di RSUD dr. Sayidiman Magetan Tahun 2014

\begin{tabular}{|c|l|c|c|}
\hline No & Kategori Sikap & $\boldsymbol{\Sigma}$ & $\mathbf{\%}$ \\
\hline 1 & Baik & 55 & 98,2 \\
\hline 2 & Cukup & 1 & 1,8 \\
\hline 3 & Kurang & 0 & 0 \\
\hline \multicolumn{2}{|l}{ Jumlah } & $\mathbf{5 6}$ & $\mathbf{1 0 0}$ \\
\hline
\end{tabular}


Tabel 5. Tindakan Perawat dalam Membuang Limbah Medis di RSUD dr. Sayidiman Magetan Tahun 2014

\begin{tabular}{|c|l|c|c|}
\hline No & $\begin{array}{c}2014 \\
\text { Kategori } \\
\text { Tindakan }\end{array}$ & $\boldsymbol{\Sigma}$ & $\mathbf{\%}$ \\
\hline 1 & Baik & 30 & 54 \\
\hline 2 & Cukup & 26 & 46 \\
\hline 3 & Kurang & 0 & 0 \\
\hline \multicolumn{2}{|l}{ Jumlah } & $\mathbf{5 6}$ & $\mathbf{1 0 0}$ \\
\hline
\end{tabular}

Tabel 6. Perilaku Perawat dalam Membuang Limbah Medis di RSUDdr. Sayidiman Magetan Tahun 2014

\begin{tabular}{|c|l|c|c|}
\hline No & Kategori Perilaku & $\boldsymbol{\Sigma}$ & $\mathbf{\%}$ \\
\hline 1 & Baik & 55 & 98,2 \\
\hline 2 & Cukup & 1 & 1,8 \\
\hline 3 & Kurang & 0 & 0 \\
\hline \multicolumn{2}{|c|}{ Jumlah } & $\mathbf{5 6}$ & $\mathbf{1 0 0}$ \\
\hline
\end{tabular}

\section{PEMBAHASAN}

1. Ruang Penghasil Limbah Medis dan Jenis Limbah Medis yang dihasilkan

Ruang penghasil limbah medis dan jenis limbah yang dihasilkan sudah sesuai.

2. Timbulan Limbah Medis oleh Perawat Dari 11 ruang terdapat 7 ruang (64\%) yang sudah melakukan pemilahan, 4 ruang (36\%) belum melakukan pemilahan. Selain tidak dipilahnya antara limbah medis dan non medis, tidak dipilahnya limbah medis yang sudah disediakan pewadahan seperti spet/jarum (limbah benda tajam) masih dibuang menjadi 1 dengan limbah medis lainnya. Meskipun sudah disediakan sendiri wadah untuk limbah benda tajam (safety box).

3. Pewadahan yang disediakan sudah memenuhi, terdapat volume tempat sampah limbah medis dan pelabelan mendapat nilai yang kurang, karena volume tempat sampah limbah medis yang disediakan volume tidak memenuhi dan jumlahnya kurang untuk menampung limbah medis yang dihasilkan yaitu ruang ruang IGDdan IRNA I.

4. Pewadahan Limbah Medis oleh Perawat Dari 11 ruang yang diteliti semuanya (100\%) limbah medis belumditempatkan sesuai pada wadah yang sudah disediakan limbah medis dan non medis, tetapi oleh perawat tidak dipilahnya limbah medis benda tajam seperti jarum suntik. Seharusnya dibuang pada safety box yang sudah disediakan, tetapi kenyataanya dijadikan satu dengan limbah medis lainnya.
5. Ketersediaan Pewadahan Limbah Medis di RSUD dr. Sayidiman Magetan

Ketersediaan pewadahan sebagian besar dalam kategori baik sebanyak 9 ruangan $(82 \%), 2$ ruangan $(18 \%)$ kategori cukup.

6. Volume Limbah Medis

Dari 11 ruang yang diteliti 7 ruang (64\%) sudah diperhatikan, 4 ruang (36\%) kurang diperhatikan. Perawat cenderung membuang pada 1 tempatsampah limbah medis saja.Sikap baik yang diperlihatkan oleh responden berkesinambungan dengan teori yang dikemukakan ahli Notoatmodjo, pengetahuan yang baik akan diiringi dengan sikap dan perilaku yang baik pula.

7. Tingkat Pengetahuan Perawat

Tingkat pengetahuan perawat dalam membuang limbah medis dari 56 responden, 42 responden (75\%) berpengetahuan baik, sedangkan 14 responden (25\%) berpengetahuan cukup. Hali ini karena 71,4\% berpendidikan setara DIII Keperawatan, bekerja lebih dari 1 tahun. Hal ini sesuai dengan yang dikemukakan ahli bahwa makin tinggi pendidikan akan menghambat perkembangan sikap seseorang terhadap nilai-nilai yang baru diperkenalkan. (Notoadmojo,2007).

8. Sikap Perawat dalam Membuang Limbah Medis

Sikap perawat dalam membuang limbah medis diperoleh 55 orang $(98,2 \%)$ pada kategori baik, 1 orang $(1,8 \%)$ berada pada kategori cukup. 42,9\% perawat bekerja lebih dari 1 tahun sehingga perawat tahu kebijakan pengelolaan limbah medis yang ada di Rumah Sakit, semakin lama bekerja pengetahuan perawat tentang membuang limbah medis dan non medis.Pada sikap dan tindakan perawat yang masih dalam kategori cukup, hal ini tidak sejalan dengan tingkat pengetahuan perawat yang dalam kategori baik. Hal ini disebabkan oleh berbagai faktor yang membuat sikap dan tindakan perawat tidak sejalan dengan tingkat pengetahuan, dipengaruhi oleh tidak adanya sangsi yang diberikan kepada ruangan-ruangan yang masih mencampurkan antara limbah medis dan non medis maupun tidak menempatkan limbah medis pada wadah yang disediakan. Dan kurangnya fasilitas yang disediakan untuk pewadahan limbah medis.

9. Tindakan Perawat

Tindakan Perawat dalam Membuang Limbah yaitu 30 orang (54\%) dalam 
kategori baik dan 26 orang (46\%) dalam kategori cukup. Tindakan merupakan tahap akhir perilaku, tindakan yang baik atau yang kurang yang dilakukan adalah pengaruh dari tingkat pengetahuan dan sikap responden, karena dipengaruhi pendidikan yang setara yakni Diploma III juga oleh sumber informasi yang cukup baik dari berbagai sumber kepada perawat meningkatkan seseorang makin mudah menerima informasi makin banyak pula pengetahuan yang dimiliki, sebaliknya pendidikan yang kurang.

10. Tingkat Perilaku Perawat

Tingkat Perilaku Perawat dalam Membuang Limbah di RSUD dr. Sayidiman Magetan 2014diperoleh bahwa perilaku perawat pada jam kerja sift pagi berada dalam kategori baik, yaitu 55 orang $(98,2 \%)$ dan 1 orang $(1,8)$ dalam kategori cukup.

\section{KESIMPULAN}

1. Ruang penghasil limbah medis adalah ruang Paviliun Wijaya Kusuma,IRNA (Instalasi Rawat Inap) I sampai VI, IBS (Istalasi Bedah Sentral),IGD (Instalasi Gawat Darurat), Poliklinik Gigi, Poliklinik Bedah. Limbah medis yang dihasilkan meliputi alat injeksi, ampul, kateter, botol bekas obat injeksi, sarung tangan, masker, kapas, kasa/perban, pisau.

2. Timbulan Limbah Medis oleh Perawat,dari 11 ruang terdapat 7 ruang (64\%) yang sudah melakukan pemilahan.

3. Pewadahan Limbah Medis oleh Perawat di 11 ruang $100 \%$ masih belum ditempatkan sesuai pada wadah yang sudah disediakan.

4. Ketersediaan pewadahan dalam kategori baik sebanyak 9 ruangan (82\%).

5. Volume limbah medis oleh perawat, terdapat 7 ruang (64\%) sudah diperhatikan.

6. Tingkat pengetahuan perawat dalam membuang limbah Medis 42 responden (75\%) berpengetahuan baik.

7. Sikap perawat dalam membuang limbah 55 orang $(98,2 \%)$ kategori baik.

8. Tindakan perawat dalam membuang limbah 30 orang (54\%) kategori baik.

9. Perilaku perawat dalam membuang limbah kategori baik 55 orang $(98,2 \%)$.

\section{SARAN}

1. Hasil limbah medis agar dikelola dengan benar sesuai prosedur yang ada.

2. Diharapkan pelabelan untuk tempat sampah limbah medis dan non medis
3. Diharapkan di ruang IGDditambah 4 tempat limbah medis dengan volume 23 liter dan 1 tempat sampah limbah medis dengan volume 80 liter yangdilengkapi tutup, untuk ruang IRNA I ditambah 1 tempat sampah limbah medis dengan volume 23 liter yang dilengkapi tutup.

4. Diharapkandiadakan sosialisasi tentang pengelolaan limbah medis di Rumah Sakit dr. Sayidiman Magetan khususnya tentang perbedaan warna pewadahan limbah medis sesuai jenis limbahnya.

5. Diharapkan membuat protap tugas secara fungsional bagi perawat sesuai dengan tingkat lulusan/pedidikan.

6. Diharapkan kepada petugas sanitarian di RSUD dr. Sayidiman Magetan agar melakukan monitoring dan evaluasi pada ruangan-ruangan penghasil limbah medis dan memberikan reward atau penghargaan kepada ruangan yang terbaik dalam mengelola limbah medis dan non medis juga diberikan punishment atau sangsi bagi ruangan yang tidak mengelola limbah medis dengan baik.

7. Diharapkan kepada petugas sanitarian RSUD dr. Sayidiman Magetan agar memeratakan pembagian tempat sampah medis khususnya safety box secara merata pada ruangan-ruangan penghasil limbah medis.

\section{DAFTAR PUSTAKA}

Anonymous, 2009. Persyaratan Kesehatan Lingkungan Rumah Sakit, Keputusan Menteri Kesehatan RI No.1204/MENKES/SK/X/2004, Jakarta. Departemen Kesehatan RI.

, 1995. Pedoman Sanitasi Rumah Sakit, Direktorat Jenderal PPM \& PLP dan Direktorat Jenderal Pelayanan Medik, Jakarta. Departemen Kesehatan RI.

Asmadi, 2013. Pengelolaan Limbah Medis Rumah Sakit. Yogyakarta. Bosyen Publising.

Septiani, B.B, 2012. Infeksi Nosokomial. Yogyakarta. Nuha Medika.

Mubarak, W., 2005. Pengantar Keperawatan Komunitas 1. Jakarta. Sagung seto.

Notoatmodjo, S., 2010. IImu Perilaku Kesehatan, Jakarta : PT Rineka Cipta.

http://ebookbrowsee.net/no/notoatmodjo\#. UxXak3ry1dIDiakses tanggal 04/03/2014 15.21 